This is an Accepted Manuscript of an article published by Taylor \& Francis in Language Awareness on 24 July 2012, available online:

http://www.tandfonline.com/doi/full/10.1080/09658416.2012.703673

(Language Awareness 2013, 22/3: 255-269)

\title{
Learners' perceptions of grammar-translation as consciousness raising
}

\author{
Pawel Scheffler
}

\section{Faculty of English, Adam Mickiewicz University in Poznań, Poland}

Foreign language teaching methodologies of the 20th century were dominated by the principle of monolingualism. Language teaching specialists and linguists of that time generally argued in their publications against using learners' own languages in the classroom and described translation as a dull activity which did not contribute anything to language learning. However, since the beginning of the 21 st century calls for a reassessment of translation have begun to appear. This article offers an argument for a reassessment of grammar-translation in language teaching based on learners' perceptions of this activity. It reports a study in which 45 secondary school Polish learners of English were asked to evaluate two consciousness-raising activities they had performed: a grammar-translation task and a communicative language exchange. The results show that the learners considered translating sentences from Polish into English to be as useful and interesting as communicatively-oriented consciousness raising.

Keywords: translation, grammar, learners' perceptions, consciousness raising

\section{Translation in the 20th century foreign language classroom}

There are many potential uses of learners' own languages in the foreign language (FL) classroom. For example, teachers can utilize their learners' L1 to explain meanings of new lexical items, to provide grammatical explanations, and to conduct the business of classroom management. Learners can also be asked by teachers to translate sentences or texts into or out of the target language. As V. Cook (2001) points out, however, there was little or no official 
support for any of these uses in leading FL teaching methodologies during much of the twentieth century. In structure-oriented methodologies (e.g. Lado 1964), learners' own languages were supposed to cause interference errors; in methodologies with a focus on meaning or interaction (e.g. Krashen and Terrell 1983, Long and Robinson 1998), they were an obstacle to maximising foreign language input.

The aspect of L1 use that was criticized the most strongly was translation into a foreign language (e.g. Sweet 1899/1964, Jespersen 1904, Lado 1964). This type of translation, along with explicit grammar instruction, was, of course, the foundation of FL teaching in the grammar-translation method, in which learners were typically asked to translate strings of disconnected invented sentences. However, with the advent of the Reform Movement in the late 19th century, such translation became completely unacceptable as an instructional tool because it contradicted the three fundamental principles of the Movement: the primacy of speech, the use of connected text, and the use of oral methodology in the classroom (Howatt 2004: 189). For Sweet (1899/1964: 72), disconnected sentences used in grammar-translation courses were unnatural and unidiomatic:

...in the practice of exercise writing and translation into the foreign language (...) [t]he result is to exclude the really natural and idiomatic combinations, which cannot be formed a priori, and to produce insipid and colourless combinations which do not stamp themselves on the memory, many of which, indeed, could hardly occur in real life .... .

Sweet 1899/1964: 7

Further, translation was in general considered to be too difficult for learners and a source of errors which otherwise would not have arisen: 
In giving the pupil English sentences to translate into the foreign language, we are only artificially creating difficulties. If it is difficult for the pupil to translate into his mother-tongue (...), then it must be much more difficult, indeed impossible, to translate into a foreign language where he is not yet quite at home. We ourselves lead the pupil to make mistakes, and then we have to do all we can to prevent his confronting us with a too overwhelming number of them.

Jespersen 1904: 123-124

Finally, translation exercises encouraged learners to think that for every word in their native language there was a FL equivalent, which is not the case because, as Jespersen (1904: 54) put it, '[the] relations between languages are not like the relations between mathematical equivalents ...'

An equally negative view of translation was independently presented more or less at the same time by proponents of natural or direct methods of teaching foreign languages. So, for Berlitz (1898: 1-2) translation could not be used in FL teaching because it interfered with direct associations that were supposed to be formed by learners between 'perception and thought' and 'the foreign speech and sound'. Also, like members of the Reform Movement, Berlitz viewed translation as an exercise leading to the learners' mother tongue (MT) 'invading the foreign idiom' and leading them to believe in exact equivalents.

The views on translation expressed by members of the Reform Movement, and, to a lesser extent, by educators like Berlitz, were adopted and in some cases developed further by linguists and language teaching professionals in the 1950s and 60s (for example Gatenby 1948/1967, Lado 1964, Brooks 1964, Halliday et al. 1964, Bennett 1968). The most outspoken critics of translation were probably Gatenby and Lado. For Gatenby (1948/1967: 
66-67), FL learning should as far as possible replicate the conditions of first language acquisition, which means that 'there is, of course, no translation'. To exclude translation Gatenby (1948/1967: 66-67) also draws upon early bilingual language acquisition and points out that in such cases the two linguistic systems develop separately and that if a bilingual child is 'called upon for an interpretation he seems to have the same difficulty as a unilingual child who is asked for a paraphrase (...)'. For Lado (1964: 53-54), a proponent of mimicrymemorization and pattern practice in FL learning, translation was an independent skill, 'more complex than, different from, and unnecessary for speaking, listening, reading, or writing'. This skill should only be taught once the others have been mastered, and asking learners to translate into a foreign language before they are ready to do so is bound to result in mistakes and incorrect constructions.

As a result of all these criticisms, translation as a teaching tool did not feature in any major teaching methods which appeared in the 20th century. The so-called alternative methods which made use of translation or translated texts (for example Curran's Community Language Learning and Dodson's Bilingual Method) did not attract much attention (three notable exceptions in the case of the latter are Marton 1978, Butzkamm 1980 and Kaczmarski 1988). Different versions of the grammar-translation method may have continued to be used in some parts of the world (Fotos 2005), but EFL teachers influenced by mainstream AngloAmerican ideas used translation much less frequently, and if they did, they generally kept quiet about it, knowing that 'it was politically somewhat incorrect to speak in its favour' (Witte, Harden, and Ramos de Oliveira Harden 2009: 1). The received view was that translation, like all traditional teaching techniques and methods, has failed:

grammatical syllabi, linguistically "simplified" teaching materials, explicit grammar explanations, immediate forced student production, pattern practice, translation, error 
“correction" $(. .).[a] s$ attested by the ratios of beginners and false beginners to finishers (...) are more frequently associated with failure, suggesting that the successful students may learn through them or in spite of them, not necessarily because of them.

Long and Robinson 1998: 20

The general attitude to translation began to change at the turn of the 21 st century and reflected a more general shift in the views on the place of the MT in the foreign language classroom. Writers like Duff (1995), Widdowson (2003), Butzkamm and Caldwell (2009) and G. Cook (2010) argued for a revision of monolingual teaching and a reassessment of translation as an instructional procedure. 'Translation has been too long in exile (...) and it is time it was given a fair and informed appraisal', Widdowson (2003: 160) said.

Such calls for reassessment were supported by research findings in two main areas of study. First, as Butzkamm and Caldwell (2009) point out, more and more evidence started to emerge that it was not possible to suppress or switch off learners' own languages. For example, word recognition and word judgement experiments showed that in bilingual persons the two semantic systems were shared and that native vocabulary was activated in tasks involving the target language (e.g. Illes et al. 1999, Weber and Cutler 2004, Thierry and Wu 2007). Second, research demonstrated that providing learners with explicit contrastive L1-L2 information contributed to L2 performance (e.g. Kupferberg and Olshtain 1996, Kupferberg 1999, Ammar, Lightbown and Spada 2010).

One can observe the change that has taken place in the attitude to translation by comparing different editions of introductions to language teaching. For example, in the second edition of The Practice of English Language Teaching by Harmer (1991: 70, 162, 
240), translation is discussed in the context of teaching vocabulary and class management. In the fourth edition of the book, Harmer (2007: 133) advises teachers to use translation to help learners make comparisons between the MT and the FL and also to check learners' understanding of grammar and lexis. Two example activities that Harmer (2007) mentions are 'straight translation of short texts' and 'a translation summary of a longer text'.

\section{Translation and SLA research}

Until the early 2000s translation was basically ignored by Second Language Acquisition researchers. As G. Cook (2010: 21) notes, recent surveys of the field fail to discuss translation as a learning activity, which in his opinion reflects what has been done in this area, i.e. 'next to nothing'. It seems, then, that most SLA researchers have taken for granted the views of Sweet, Jespersen, Lado and the like, and considered investigating translation empirically to be a waste of time.

The work that has been done in the field of SLA concerned mainly the usefulness of translation in the area of testing (e.g. Buck 1992, Ito 2004), the acquisition of lexis (e.g. Källkvist 1998, Laufer and Girsai 2008, Hummel 2010), the teaching of writing (Kobayashi and Rinnert 1992, Uzawa 1996, Cohen and Brooks-Carson 2001, Kim 2011), grammar Källkvist (2004, 2008), and classroom discourse (Kälkvist in press). In the context of grammar instruction, which is relevant to the present study, Källkvist (2008) concluded that translation exercises lead to improvements on measures of grammatical accuracy. She also found that there was little difference between the effectiveness of translation versus monolingual practice involving gap-filling exercises and paraphrases. However, these results can only be treated as very tentative. Källkvist herself (2008) stresses that her study involved small groups of participants and relatively few test items, and that more research is needed 
before any definitive conclusions can be formulated concerning the place of translation in L2 teaching.

An area in which there is also a dearth of research is learners' beliefs concerning translation, particularly in the secondary school context. For a long time very negative views have been ascribed to learners, but as Cook (2010: 9) says, they have only been supported with 'anecdotal evidence (often based on the advocate's own memories of school)'. A case in point here is Sweet (1899/1964: 73) and his famous example about the philosopher pulling the lower jaw of the hen, which is supposed to illustrate how unnatural and unidiomatic the sentences in grammar-translation exercises were.

His view was shared by Jespersen (1904), who had this to say about the appeal of grammar-translation exercises to learners:

And should it not also be of some significance to attract the interest of the pupils? Nothing seems hard to a willing mind. That which is associated with pleasant recollections has a firmer place in the memory than dry stuff. But exercises where it alternates between the Frenchman who has taken the Englishman's hat and the Englishman who has taken the Frenchman's cane, or where either Marie sees Louise's dog or Peter sees Henry's horse - they cannot be anything but boring, even if they give the pupils ever so gradual practice in the use of the genitive.

Jespersen 1904: 15

The grammar-translation method was not, however, just boring. It often caused frustration for pupils because learning a foreign language involved "a jungle of obscure rules, endless lists of gender classes and gender-class exceptions, self-conscious "literary" archaisms, snippets of philology, and a total loss of genuine feeling for living language' (Howatt 2004: 156). The 
forms and rules were normally practised in strings of uninterrupted, yet generally unrelated sentences. The following examples were supposed to be translated by English learners into German to practise various forms of the verb sein:

He will soon be in London. Will he be the guide? I shall have been here an hour. You will be very tall. It will be early enough. We shall have been very angry. He would be clever, if he were attentive. If he were attentive, he would be clever. I should have been a fool, if I had been so careless. Be so kind, my friend. Let it be so. We shall be sincere. Should we have been his enemy. Let us always be faithful. It would have been better, if we had not had it. She would be amiable, if she were not so talkative.

Tiarks 1837:3

The implementation of grammar-translation described above justifies such a harsh judgement and there is little wonder that such courses were 'remembered with distaste by thousands of school learners' (Richards and Rodgers 2001: 6).

However, if translation is used sparingly in those cases in which it can help learners to realize certain contrasts between L1 and L2, then learners can see the benefits it can bring. One study that demonstrates this is Kim (2011). It deals with translation as a tool for improving writing skills, and one of the areas it concerns is grammar. In the study, low-level Korean college students of English were asked to translate into their native language their own and their classmates' compositions written in English. The translation exercises proved very effective as consciousness raising tasks: while previously the drafting process resulted in few improvements in the quality of their writing, following the exercises the learners were 
able to see many inadequacies both in the content of the drafts and in their form. These are typical comments from two of Kim's students:

After I translated my writing into Korean, I discovered a lot of mistakes. There were many unconnected sentences. I think translating our own writing into Korean is important in order to measure our true writing skill.

I had to revise my writing four times when I was translating. Some sentences are smoothly connected, but others were a little too forced. I also realized that I missed some details because I was concentrating on my English. I like my introduction better this time. I could discover my mistakes more easily when I translated my composition into Korean.

Kim 2011: 157

When learners are asked to provide a more general assessment of the role of translation in their learning, their responses are often positive. That was the case in Liao's (2006) largescale study, in which a questionnaire concerning beliefs about translation was administered to 351 college students in Taiwan. The participants were asked to respond to 24 statements which had to do with the role of translation in learning productive and receptive language skills, grammar, lexis and also with how the use of translation affects, inter alia, motivation and learning anxiety. The students' responses demonstrate that they view translation as a positive force in their learning. This applies in particular to the skills of reading, writing and speaking, and to vocabulary and idioms. The students were less convinced that their ability to understand English grammar rules was fostered by translating. Also, those of Liao's (2006) 
subjects who majored in English tended to be less positive in their assessment of translation than those who majored in other areas.

A questionnaire concerning third level students' attitudes towards translation was also part of Whyatt's (2009) project. The participants of the project, who were in BA and MA English degree courses at a Polish university, were administered the questionnaire following a text translation task. They evaluated the task as 'highly motivating', 'intellectually challenging' and enjoyable. Almost all of the BA students, for whom attending translation classes was mandatory, said that they would like to attend them even if they were not required to do so.

\section{The study}

\section{Aims}

The research findings reviewed in the previous section indicate that college level learners appreciate the benefits of translating their own writing into their MT, and that, in general, university students believe that translation facilitates the learning process, at least in some areas. The aim of this article is to provide an assessment of secondary school learners' views concerning grammar-translation as an activity raising L2 grammatical awareness and to compare it with a grammar consciousness raising activity of a more communicative kind. The study should, therefore, be relevant to a very large group of teachers working in the secondary school context.

The present study investigates the views on translation held by secondary school rather than university learners of English. The two populations may be expected to differ in how they perceive the usefulness of translation in the learning process. University students are 
older, they may often be more proficient in English, and if they are English majors, which was the case with all Whyatt's (2009) and most of Liao's (2006) subjects, then they may have a special interest in English and in translation itself. Also, students majoring in English teaching are normally exposed to various (negative) accounts of translation in language teaching, which may influence how they feel about its usefulness.

In grammar-translation courses, translation of strings of unrelated sentences was often used to practise newly introduced grammar rules. As has been stated, this attracted severe criticism from numerous language teaching experts and was disliked by learners. In this study, an attempt is made to determine whether translating disconnected sentences can be perceived by learners as a useful means of illustrating grammatical phenomena. The sentences will, however, differ from the ones in grammar-translation courses in two important ways. First, they will be used to review rather than introduce grammar. Second, they will be selfcontained and clearly separated from one another so that each of them can be easily interpreted by the learners.

\section{Materials and procedure}

The study was performed in a randomly selected secondary school in the author's province. The subjects were 45 intermediate learners aged 16-19, 26 male and 19 female. The pupils formed three randomly selected intact classes in which the following procedure was used. First, the author performed a grammar-translation activity in the three groups. The translation component can be described as 'form-focused close translation', i.e. translation in which learners are supposed 'to keep as close as possible to the original' (G. Cook 2010: 136). Immediately after the activity the pupils were asked to fill in a questionnaire about it. After a four-week break, the same sequence was used for the communicative activity. Finally, again 
after a four-week interval, the pupils attended one more translation session and a communicative session, but this time they were asked to provide spontaneous comments about them. The timing of the sessions was motivated primarily by the availability of the pupils. Also, as they were available for only 45-minute periods at a time, the questionnaire and the spontaneous comments sessions needed to be separated. This may have had the added bonus of the pupils not being directly influenced in their comments by the content of the questionnaire.

In both of the activities, the forms in focus were tense and aspect, something that the pupils were familiar with from previous instruction. Polish and English differ considerably in this area of grammar, and as for example Scheffler (2010) shows, this area is a source of problems for Polish learners. The sentences below are examples of tense and aspect errors made by Polish learners in communicative writing tasks. They illustrate the types of problems that Polish learners have with the following contrasts or phenomena (Scheffler 2010: 160161):

(1) Present Perfect vs Simple Present

I live here all my life. I think it is the best place in the world.

(2) Simple Present vs Present Continuous

Every Saturday I am playing football with my friends.

(3) Simple Past vs Present Perfect 
First we unpacked and put up our tent. After we have done that we went for a swim.

(4) Backshift

I wanted to see how far from the hotel I am.

The incorrect verb forms in (1) and (4) can be attributed to the influence of Polish: in the former, the present tense would be used, in the latter, the backshift rule would not be applied. The sentences in (2) and (3) are examples of overuse of the Present Continuous and the Present Perfect respectively, two non-existent categories in Polish grammar.

In the grammar-translation activities, the learners worked in pairs on four sets of disconnected sentences to translate from Polish into English, each set containing from four to six items dealing with one of the problems illustrated above (see the Appendix). The sets were not marked for the type of issue they focused on. Some of the items for translation were modified versions of sentences from Scheffler (2004). For example:

(1) I have loved Jola Rutowicz since I first saw her.

(2) Wherever Dr. Bean goes, he always causes trouble.

(3) Zenek had a busy day yesterday: first he repaired the tractor and then he painted the fence.

(4) At first it seemed that the bear was asleep, but we later noticed that it was watching us very closely.

In each translation task, the learners were provided with Polish equivalents of selected vocabulary items. The researcher also acted as a helper and in some cases provided the pupils with hints concerning the correct choice of verb forms and vocabulary. This involved pointing 
out incorrect grammatical choices and suggesting more appropriate vocabulary items. On translating the sentences, the pupils were asked to formulate rules in Polish which accounted for the grammatical structures used. The task performed by the learners can, thus, be described as a grammar-translation task.

The communicative-oriented consciousness raising activity was modelled on Fotos (1994). The learners worked in pairs and asked each other sets of questions exemplifying the same grammatical structures as in the translation exercise. There were four disconnected questions per set. The examples below come from the Present Perfect, Present Simple, the Simple Past and the Past Continuous sets respectively (the sets were not marked for grammatical categories):

(1) How long have you had your computer?

(2) Do you help your friends to prepare for tests at school?

(3) What time did you finish your classes yesterday? What did you do next?

(4) What were you doing when the news came of the President's plane crash in April last year?

The questions in most cases led to the use of the target grammar by the pupils. After the question-and-answer exchange in each set, the pupils formulated the relevant grammar rules in English. They were asked to speak English all the time during the activity. The researcher sometimes joined in some of the conversations to clarify things or to ask follow-up questions, which sometimes contained forms other than those in focus.

In the questionnaire, semantic differential scales were applied. They consisted of three sets of bipolar pairs of Polish adjectives, as in the translated example below: 
useful :__ useless

Each set contained five pairs of adjectives and was supposed to measure a different category: general evaluation, utility and interest. The categories are modified versions of the ones developed by Gardner (1985), who used them to examine learners' assessment of a language course. The following are English translations of the Polish adjectives that were used in the study (Table 1). In the questionnaire, the ordering of the adjective pairs was random and the position of the 'positive' and 'negative' poles alternated between the right and the left side. Before the pupils filled in the questionnaire, they received detailed written instructions on how to proceed based on Appendix A.3 in Gardner (1985).

Table 1: English translations of Polish adjectives

\begin{tabular}{lll}
\hline \multicolumn{1}{c}{ general evaluation } & \multicolumn{1}{c}{ utility } & \multicolumn{1}{c}{ interest } \\
\hline good - bad & useful - useless & interesting - uninteresting \\
agreeable - disagreeable & educational - uneducational & absorbing - monotonous \\
pleasant - unpleasant & needed - unneeded & exciting - boring \\
enjoyable - unenjoyable & necessary - unnecessary & varied - monotonous \\
nice - awful & effective - ineffective & inviting - off-putting \\
\hline
\end{tabular}

The answers indicated by the pupils were converted into numerical values. So, for example, a check mark right next to 'useful' was worth seven points (extremely positive assessment), and one immediately beside 'useless' was worth one point (extremely negative assessment). A check mark in the middle of the scale signified neutral assessment and was worth four points. Because there were five pairs of adjectives in each category, the minimum possible score was five, and the maximum was 35 . The internal consistency of the scales (i.e. the fact that for 
each category they worked together as a homogenous set) was confirmed by the Cronbach Alpha coefficient, the value of which in each case exceeded 0.7 (cf. Dörnyei 2003: 112). The exact values for each category are given in Table 2 .

Table 2: Cronbach alpha coefficients

\begin{tabular}{lc}
\hline \multicolumn{1}{c}{ Category } & Cronbach alpha \\
\hline Translation general & 0.795 \\
Translation utility & 0.837 \\
Translation interest & 0.704 \\
Communication general & 0.809 \\
Communication utility & 0.832 \\
Communication interest & 0.830 \\
\hline
\end{tabular}

\section{Results and discussion}

Figure 1 below shows the distribution of the scores for each category. It is a box-and-whisker plot which has the following characteristics. First, the horizontal line in each box is the median, i.e. the middle point in the distribution: 50 percent of the scores fell below those points, and 50 percent above. Second, the lower end of each box is the first quartile, one fourth of the data lies below it. Third, the upper end of each box is the third quartile, one fourth of the data lies above it. Finally, the ends of the whiskers mark the maximum and minimum scores. 
Figure 1: distribution of the scores for each category

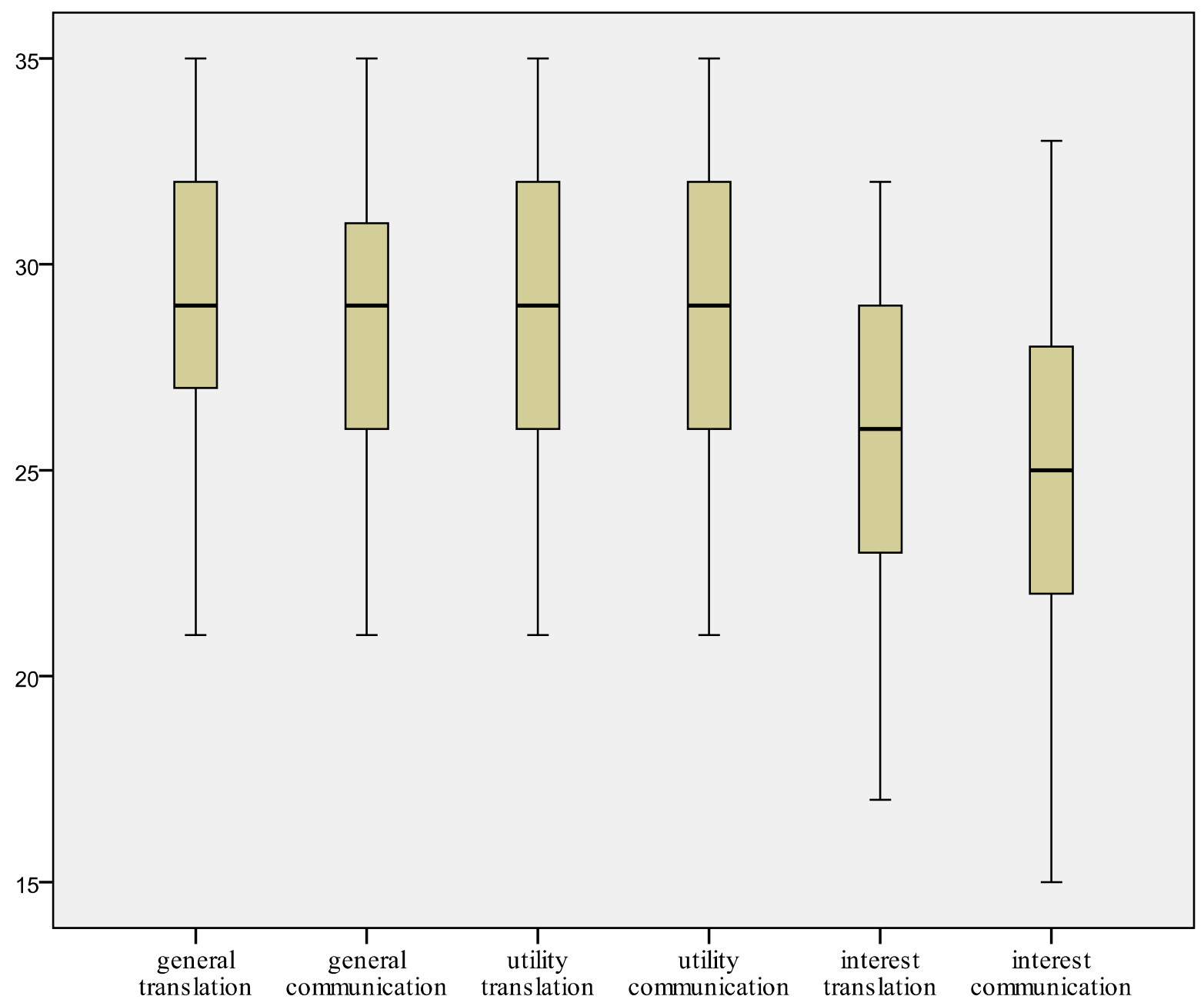

Two general observations can be made about the distributions in Figure 1. First, the pupils gave a positive endorsement to both of the activities, particularly in the general evaluation and utility categories. In these categories, the medians are 29 , which is well above the neutral assessment level of 20 points, and there are no scores below that level. The assessments in the 
interest category were less positive, but here also the centres of the data lie above the neutral level (the medians are 26 and 25 for the translation and communication activity respectively).

A more detailed breakdown of the positive scores can be seen in Table 3. The positive spectrum is divided there into three levels: 21-25 points - moderately positive assessment, 2630 positive assessment, and 31-35 very positive assessment. This clearly shows how general evaluation and utility differ from interest: there are about four times as many very positive assessments in the former as in the latter.

Table 3: Levels of positive assessment

\begin{tabular}{ccccccc}
\hline & general & general & utility & utility & interest & interest \\
& translation & communication & translation & communication & translation & communication \\
\hline $21-25$ & 5 & 11 & 11 & 10 & 17 & 20 \\
$26-30$ & 25 & 19 & 19 & 19 & 22 & 4 \\
$31-35$ & 15 & 15 & 15 & 16 & 3 & 4 \\
\hline
\end{tabular}

The second general observation concerning Figure 1 is that the distributions for translation and communication in each category appear to be very similar. In order to verify whether the differences that do occur are statistically significant, the Wilcoxon Signed-Rank Test was performed on the sets of scores from each category. As Table 4 shows, the results indicate that the differences are not statistically significant: in each case the p value is larger than 0.05 . We can safely conclude, then, that the pupils perceived the two activities as equally good, useful and interesting.

Table 4: test statistics

\begin{tabular}{lccc}
\hline & general evaluation & utility & interest \\
\hline test statistic $(Z)$ & -0.797 & -0.665 & -0.626 \\
\hline
\end{tabular}


Semantic differential scales are closed-ended items. They tell us, for example, that pupils consider translation activities to be useful but they do not say why pupils think that way. To learn more about this, and also to identify issues not covered by the questionnaire, we need to turn to the part of the study in which the pupils were asked to contribute spontaneous comments about the activities.

The learners were asked to provide written comments in Polish about any aspect of the activities immediately after they performed them. The vast majority of those comments were positive and they concerned both some specific features of each type of activity (e.g. usefulness) and the way in which the activities were organized (e.g. pair work). The following key points were raised by the pupils concerning the grammar-translation exercise:

- translation is a good way of showing differences between Polish and English

- the sentences clearly showed the use of verb forms in English

- the sentences were in general interesting

- unusual sentences are easy to remember

- working in pairs made the task absorbing

- the teacher's involvement was helpful

- translation exercises make a break from classroom routine

It seems that the key points above can be grouped into three main categories: evaluation of the usefulness of the activity, evaluation of the sentences, and evaluation of the implementation. Here are five comments that the pupils actually contributed (translated into English by the author): 
Exercises of this type show differences between Polish and English. A big plus was that we also learnt which words were appropriate for a particular situation. The sentences were interesting, working in pairs made the task more absorbing.

It was a good exercise because it helped me to transfer my thoughts into English.

Comparing sentences helps to understand how English people think.

It was a useful exercise. It showed us in a very direct way how to use English tenses.

Such exercises are not used very often and because of that I found them engaging. I like exercises which are different from the ones that we routinely do in the classroom.

It was good that the sentences were divided into sections, each dealing with a different tense. It made it easier to remember the situations in which they were used.

The examples in the exercise were invented disconnected sentences (in a few cases they were sequences of two related sentences): it was assumed that it would be easier for learners to deal with grammatical phenomena in sentences rather than in longer stretches of text. This does not mean that short texts may not be used as translation exercises: there are cases in which a text is necessary to illustrate a grammatical point. It should, however, be verified empirically whether learners can handle such grammatically-oriented translation exercises and whether they find it easier to focus on grammar in isolated sentences. 
The disconnected nature of the sentences proved not to be a problem for the pupils: as evidenced by some of the comments, the situations described by the sentences were clear and they helped the pupils to 'understand how English people think' and how English verb forms are used. It seems then, that a disconnected sentence need not be 'meaningless', as for example Halliday et al. (1964: 266) and Lewis (1993: 13) say, and that it can be used to illustrate a grammatical point. This actually confirms what Sweet (1899/1964: 100) said: even though he was, of course, in favour of employing connected text in teaching, he also saw the value of detached illustrative examples:

But in a grammar, the rules must be illustrated and justified by examples, which also serve to strengthen the learner's hold of the rule, and to make it easier for him to recognize the working of the rule in the texts he reads. These examples must in the nature of things be detached words or detached sentences.

He added to that that only such sentences should be used 'which will really bear detaching'. And, as in this study, it should also be made clear to learners that they are detached sentences, i.e. they should be presented as separate items, and not as uninterrupted strings, which was normally the case in grammar-translation textbooks.

It is also interesting to note the comments concerning the fact that unusual sentences are easy to remember. This point could be related to G. Cooks' (2001) defence of the invented sentence as a tool in FL teaching, and the debate between V. Cook (2002) and G. Cook (2003) on this issue. The pupils who made those comments seem to support G. Cook's position: for them it is not the case that '[the] message of the input sentences could be anything at all, provided they contain the necessary language elements on which the language can build (...)' (V. Cook 2002: 265). Rather, the unusual message makes a sentence, and perhaps a 
grammatical construction it contains, more memorable. The pupils did not specify in their comments which sentences they found unusual. It would be interesting to find out what it is in general that learners find unusual and memorable in an example sentence, and whether, and if so in what way, this contributes to better language use and language development. One possibility is that individual examples, if learners can recall them verbatim, may be used as models for creating novel sentences in a foreign language (G. Cook 2001: 382).

The translation activity in the study was performed by the pupils in pairs. The reason for this was to make the two activities the same in terms of grouping the learners. During the activity, which was introduced in Polish, the pupils communicated in their native language to discuss various grammatical and lexical issues. The comments made by some of them indicate that they found such collaborative translation a good thing. There was only one response in which a pupil said he /she would have preferred to translate the sentences on his / her own.

The comments concerning the communicatively-oriented activity centred around the usefulness of combined speaking and grammar practice and the choice of the topics for the exchanges. The latter goes beyond grammar teaching methodology, but it seems nevertheless interesting. The following are five translations of pupils' actual responses:

It is easier to learn grammar by talking about it than by reading rules.

It was a good exercise. We practised both speaking and grammar.

Most questions were interesting and original. I don't think, though, that the one about boyfriends / girlfriends was a good idea. 
The exercise was a little repetitive, but in general it was OK. One must be careful with questions about the Smolensk plane crash, though!

Talking about grammar in English is better than writing sentences. The conversation about the plane crash was interesting.

As the last three comments demonstrate, it is not easy to select topics that would be acceptable to everyone. It seems that while trying to get learners engaged by having them discuss issues potentially relevant to them, care should be taken not to touch upon sensitive issues, as the following question from the Past Continuous set might have done:

What was your boyfriend / girlfriend doing when you first saw him / her?

The final two points in relation to pupils' comments apply to both activities and concern the researchers' performance as a teacher and the novelty factor. First, as has been mentioned, in each case the researcher moved around the classroom and acted either as a resource or an extra participant, by for example asking follow-up questions in the communicative activity. Both of these roles were evaluated positively by the pupils: as some of them stated, they appreciated the guidance and support they had received. Second, the pupils' responses, particularly in the case of translation, may have been influenced by the novelty factor: the translation exercise was completely new to them, and the specific design of the communicative activity was also an innovation for this group of pupils.

\section{Conclusion}


The present article is a report on a small-scale study. What the findings indicate is that for pupils from a typical Polish secondary school, translation combined with metalinguistic reflection is a welcome activity, comparable to communicatively-oriented consciousness raising. So while in the days of the grammar-translation method the study of grammar rules combined with translation may have been something that many pupils dreaded, it is now described by them as a refreshing change from regular classroom activities. That there should be no return to the excesses of grammar-translation teaching was made clear by one of the pupils, who stated that while the activity was useful it was not something he / she would like to do all the time. This means that the activity administered to pupils in this study can certainly be improved: in particular, it seems that changes could be introduced to make it more interesting, as the scores in this category were lower than in the other two. This could perhaps be done by using more topics which are of immediate relevance to particular age groups of learners. Also, learners could be provided with partially translated sentences and not just with translations of selected vocabulary items, which was the case in the exercises in this study. This would guide them in the process of translation and would enable them to focus more easily on specific grammatical points.

Whether translation actually leads to improvements in the accuracy of learners' performance is an empirical question which should be settled by research. Becoming aware of an L1-L2 contrast through translation may often involve making an error during the activity, but since this is supposed to be an accuracy-oriented activity such errors should be corrected and explained immediately. This may be the first step in practicing them away.

The pupils in the study described the translation activity as useful in helping them understand aspects of English grammar. This is something that teachers should not ignore: acknowledging learners' feelings and expectations can contribute to the learning process by making learners feel more secure and confident. Translation cannot be the foundation of FL 
teaching, as was the case in the grammar-translation method, but on the basis of this study it might be argued that it can be employed by teachers as an occasional consciousness-raising activity to review areas of grammar in which L1 - L2 contrasts are known to be difficult for learners.

\section{References}

Ammar, A., Lightbown, P.M. \& Spada, N. (2010). Awareness of L1/L2 differences: does it matter? Language Awareness, 19(2), 129-146.

Bennet, W.A. (1968). Aspects of Language and Language Teaching. Cambridge: Cambridge University Press.

Berlitz, M. D. (1898). The Berlitz Method for Teaching Modern Languages. English Part. New York: M.D. Berlitz.

Brooks, N. (1964). Language and Language Learning. New York: Harcourt, Brace \& World.

Buck, G. (1992). Translation as a language testing procedure: does it work? Language Testing, 9(2), 121-148.

Butzkamm, W. (1980). Praxis und Theorie der bilingualen Methode. [Theory and Practice of the Bilingual Method]. Heidelberg: Quelle \& Meyer.

Butzkamm, W. \& Caldwell J.A.W. (2009). The Bilingual Reform: A Paradigm Shift in Foreign Language Teaching. Tübingen: Gunter Narr Verlag.

Cohen, A. D. \& Brooks-Carson A. (2001). Research on direct versus translated writing: Students' strategies and their results. The Modern Language Journal, 85(2), 169-188

Cook. G. (2001). 'The philosopher pulled the lower jaw of the hen'. Ludicrous invented sentences in language teaching. Applied Linguistics 22(3), 366-387.

Cook, G. (2003). The functions of example sentences: a reply to Vivian Cook. Applied Linguistics, 24(2), 249-255. 
Cook, G. (2010). Translation in Language Teaching: An Argument for Reassessment. Oxford: Oxford University Press.

Cook, V. (2001). Using the first language in the classroom. Canadian Modern Language Review, 57(3), 402-423.

Cook V. (2002). The functions of invented sentences: A reply to Guy Cook. Applied Linguistics, 23(2), 262-269.

Dörnyei, Z. (2003). Questionnaires in Second Language Research: Construction, Administration and Processing. Mahwah, NJ: Lawrence Erlbaum.

Duff, A. (1995). Translation. Oxford: Oxford University Press.

Fotos, S. (1994). Integrating grammar instruction and communicative language use through grammar consciousness-raising tasks. TESOL Quarterly, 28(2), 323-351.

Fotos, S. (2005). Traditional and grammar translation methods for second language teaching. In E. Hinkel (Ed.), Handbook of Research in second language teaching and learning (pp. 653-670). Mahwah, NJ: Lawrence Erlbaum.

Gardner, R.C. (1985). The Attitude/Motivation Test Battery: Technical Report. Available at http://publish.uwo.ca/ gardner/docs/AMTBmanual.pdf (accessed 19 January 2011).

Gatenby, E.V. 1948/1967. Translation in the classroom. ELT Journal II(8), 214-218.

[Reprinted in: W.R. Lee (Ed.), 1967, E.L.T. Selections 2: Articles from the Journal 'English Language Teaching' (pp. 65-70). London: Oxford University Press]

Halliday, M.A.K., McIntosh A., \& Strevens P. (1964). The Linguistic Sciences and Language Teaching. London: Longmans.

Harmer, J. (1991). The Practice of English Language Teaching. (Second edition). Harlow: Longman

Harmer, J. (2007). The Practice of English Language Teaching. (Fourth edition). Harlow: Longman. 
Howatt, A.P.R. (2004). A History of English Language Teaching. (Second edition). Oxford: Oxford University Press.

Hummel, K. M. (2010). Translation and short-term L2 vocabulary retention: Hindrance or help? Language Teaching Research, 14(1), 61-74.

Illes, J., Francis, W. S., Desmond, J.E., Gabrieli, J.D.E., Glover, G.H., Poldrack, R., Lee, C.J., Wagner, A.D. (1999). Convergent Cortical Representation of Semantic Processing in Bilinguals. Brain and Language 70(3), 347-363.

Ito, A. (2004). Two types of translation tests: their reliability and validity. System 32(3), 395405.

Jespersen, O. (1904). How to teach a foreign language. London: Allen and Unwin.

Kaczmarski, S.P. (1988). Wstęp do bilingwalnego ujęcia nauki języka obcego [Introducing a Bilingual Approach to Foreign Language Teaching and Learning.] Warsaw:

Wydawnictwa Szkolne i Pedagogiczne.

Källkvist, M. (1998). How different are the results of translation tasks? A study of lexical errors. In K. Malmkjær (Ed.), Translation and Language Teaching: Language Teaching and Translation (pp. 77-87). Manchester: St. Jerome.

Källkvist, M. (2004). The effect of translation exercises versus gap-exercises on the learning of difficult L2 structures. Preliminary results of an empirical study. In K. Malmkjaer (Ed.), Translation in Undergraduate Degree Programmes. Amsterdam, Philadelphia: John Benjamins.

Källkvist, M. (2008). L1-L2 translation versus no translation. In L. Ortega and H. Byrnes (Eds.), The Longitudinal Study of Advanced L2 Capacities (pp. 182-202). New York: Routledge.

Källkvist, M. (in press) Languaging in translation tasks in a university setting: particular potential for student initiative and activity? The Modern Language Journal. 
Kim, E.Y. (2011). Using translation exercises in the communicative writing classroom. ELT Journal, 65(2), 154-60.

Kobayashi, H. \& Rinnert, C. (1992). Effects of first language on second language writing: Translation versus direct composition. In A. H. Cumming (Ed.), Bilingual performance in reading and writing (pp. 223-255). Amsterdam: Benjamins.

Krashen, S.D. \& Terrell, T.D. (1983). The Natural Approach: Language Acquisition in the Classroom. Oxford: Pergamon.

Kupferberg I. (1999). The cognitive turn of contrastive analysis: Empirical evidence. Language Awareness 8(3-4), 210-222.

Kupferberg I. \& Olshtain, E. (1996). Explicit contrastive instruction facilitates the acquisition of difficult L2 forms. Language Awareness, 5(3-4), 149-165.

Lado, R. (1964). Language Teaching: A Scientific Approach. New York: McGraw-Hill.

Laufer, B. \& Girsai, N. (2008). Form-focused instruction in second language vocabulary learning: A case for contrastive analysis and translation. Applied Linguistics, 29(4), 694716.

Lewis, M. (1993). The Lexical Approach. London: Language Teaching Publications.

Liao, P. (2006). EFL learners' beliefs about and strategy use of translation in English learning. RELC, 37(2), 191-215.

Long, M. H. \& Robinson, P. (1998). Focus on form. Theory, research and practice. In C. J. Doughty \& J. Williams (Eds.), Focus on Form in Classroom Second Language Acquisition (pp. 15-41). Cambridge: Cambridge University Press.

Marton, W. (1978). Dydaktyka języka obcego w szkole średniej. Podejście kognitywne. [Foreign Language Teaching in Secondary School. A Cognitive Approach.] Warszawa: Państwowe Wydawnictwo Naukowe. 
Richards, J. C. \& Rodgers, T.S. (2001). Approaches and Methods in Language Teaching. Cambridge: Cambridge University Press.

Scheffler, P. (2004). Repetytorium gramatyczne $w$ zdaniach do ttumaczenia. [English Grammar in Sentence Translations]. Poznań: LektorKlett

Scheffler, P. (2010). Ucz się na błędach. (Część 1). Języki Obce w Szkole 1, 158-173.

Sweet, H. (1899/1964). The Practical Study of Languages: A Guide for Teachers and Learners. London: Dent. [Republished by Oxford University Press, 1964, edited by R. Mackin.]

Thierry, G. \& Wu, Y.J. (2007). Brain potentials reveal unconscious translation during foreign language comprehension. PANAS 30/104, 12530-12535.

Tiarks, J.G. (1837). Exercises for Writing German, Adapted to the Rules of His German Grammar. (Second edition). London: Wacey, Black and Armstrong, Taylor, Hurst.

Uzawa, K. (1996). Second language learners' process of L1 writing, L2 writing, and translation from L1 to L2. Journal of Second Language Writing 5(3), 271-294.

Weber, A \& Cutler, A. 2004. Lexical competition in non-native spoken-word recognition. Journal of Memory and Language 50(1), 1-25.

Whyatt, B. (2009). Translating as a way of improving language control in the mind of an L2 learner: Assets, requirements and challenges of translation tasks. In A, Witte, T. Harden, \& A. Ramos de Oliveira Harden (Eds.), Translation in Second Language Teaching and Learning (pp. 181-202). Frankfurt: Peter Lang.

Widdowson, H. G. (2003). Defining Issues in English Language Teaching. Oxford: Oxford University Press.

Witte, A., Harden, T., \& A. Ramos de Oliveira Harden (2009). Introduction. In A. Witte, T. Harden, \& A. Ramos de Oliveira Harden (Eds.), Translation in Second Language Teaching and Learning (pp. 1-12). Frankfurt: Peter Lang. 


\section{Appendix}

The sentences below are correct translations of the Polish sentences used in the study.

Present Perfect

1 - How long have you had this tortoise? - Henryk has been in our family for about eighty years.

2 I have loved Jola Rutowicz since I first saw her.

3 I have worked in this school for 50 years. I think it's time for a change.

4 I have been in prison for six months. I have a lot of close friends here.

Simple Present

1 Wherever dr Bean goes, he always causes trouble.

2 Whenever I ask Zenek for help, he pretends to be busy.

3 I spend too much time at the desk. I should take more exercise.

4 Uncle Mietek has a parrot which speaks fluent English.

Simple Past

1 Zenek had a busy day yesterday: first he repaired the tractor and then he painted the fence.

2. I looked out of the window and saw a guy in a bear suit on a bench in front of the house. I went outside and it turned out that it was uncle Mietek.

3 I arrived home very late yesterday. I only drank a glass of milk and went to bed.

4 I worked as a university lecturer for ten years. Then I set up my own business.

Past Continuous and backshift

1 None of us knew then that the lions had got out of the cage and were running in the park.

2 At first it seemed that the bear was asleep, but we later noticed that it was watching us very 
closely.

3 I complained to them that my room was small. They didn't want to give me a bigger one, so I moved out.

4 I told them that I was in a hurry. But in fact I had a lot of time.

5 He didn't tell them where the money was hidden so they cut off one of his fingers.

Fortunately, we set him free the following day.

6 They asked me if I liked his new book. I lied and said that I did. 